\title{
Ateroembolia de colesterol
}

\author{
Laura Tarjuelo Gutiérrez $z^{\mathrm{a}}$, Isabel Ponce García ${ }^{\mathrm{b}}$, Fabiola Rodríguez Tebarb, \\ Lorena Moreno de la Rosa ${ }^{c}$ y Rafael Jordán Castillo ${ }^{d}$
}

aMIR de Medicina de Familia y Comunitaria. Gerencia de Atención Integrada de Albacete. Centro de Salud Zona 8. Albacete. España.

${ }^{\mathrm{b} E s p e c i a l i s t a ~ e n ~ M e d i c i n a ~}$ de Familia y Comunitaria. Gerencia de Atención Integrada de Albacete. Centro de Salud de Alcadozo. Albacete. España.

'MIR de Medicina de Familia y Comunitaria. Gerencia de Atención Integrada de Albacete. Centro de Salud Zona 4. Albacete. España.

dDiplomado en Enfermería. Gerencia de Atención Integrada de Albacete. Centro de Salud de Alcadozo. Albacete. España.

\section{Correspondencia:}

Laura Tarjuelo Gutiérrez.

Centro de Salud Zona 8

(Albacete). C/ Graduados S/N.

CP: 02006. Albacete. España.

Correo electrónico:

lauratarju21@hotmail.com.

Recibido el 10 de diciembre de 2014.

Aceptado para su publicación el 8 de abril de 2015 .

\section{RESUMEN}

La ateroembolia de colesterol (AEC) es una enfermedad sistémica poco conocida y con un pronóstico sombrío. En estas últimas décadas, su incidencia ha aumentado considerablemente. El diagnóstico es difícil y parte de una alta sospecha clínica, dada la inespecificidad de sus síntomas y el frecuente inicio tardío, semanas después de haber estado expuesto a factores predisponentes (procedimientos endovasculares, tratamiento anticoagulante). Se confirma por la biopsia del órgano afectado.

A continuación presentamos un caso clínico de una paciente con AEC de origen espontáneo que presentaba manifestaciones cutáneas, donde la sospecha clínica de esta enfermedad fue la clave para su diagnóstico y un temprano manejo terapéutico.

PALABRAS CLAVE: Embolismo de colesterol. Aterosclerosis. Factores de riesgo cardiovascular.

\section{ABSTRACT}

\section{Cholesterol atheroembolism}

Cholesterol atheroembolism (CAE) is a rarely known systemic disease with bad prognosis. In the last decades, the incidence of this disorder has increased considerably. The diagnosis is difficult and starts with a clinical suspicion, given the lack of specific symptoms and the frequent late onset during the weeks after exposure of the patient to predisposing factors (angiographic procedures or anticoagulant treatments). It is confirmed by biopsy of the affected organ.

Below we report the case of a patient with spontaneous CAE who presented skin manifestations, where clinical suspicion of this disease was the key to diagnosis and early therapeutic management.

KEY WORDS: Embolism, Cholesterol. Atherosclerosis. Cardiovascular risk factors.

\section{INTRODUCCIÓN}

La ateroembolia de colesterol (AEC) es una enfermedad sistémica con una importante morbimortalidad, producida por el impacto de cristales de colesterol procedentes de la ruptura de placas de ateroma de grandes arterias proximales que migran a arterias distales de pequeño a mediano calibre ${ }^{1,2}$.

Su incidencia se ha incrementado debido a que cada vez se encuentra más población susceptible que presenta diabetes mellitus, hipertensión arterial o dislipidemia, y que además está expuesta a factores que lo desencadenan, como procedimientos endovasculares e inicio de tratamiento anticoagulan$\mathrm{te}^{3}$.

Las medidas preventivas, con el control estricto de los factores de riesgo cardiovascular (FRCV), son la mejor opción terapéutica, ya que su manejo resulta complicado, porque no hay un consenso sobre las medidas a tomar cuando se desencadena el cuadro 4,5 . 


\section{OBSERVACIONES CLÍNICAS}

Paciente mujer de 54 años que consultó en el centro de salud por dolor en dedos y tobillo izquierdo de quince días de evolución, sin traumatismo previo ni otros síntomas acompañantes.

Como antecedentes personales de interés destacaba tabaquismo activo de 20 cigarrillos/día, hipertensión arterial (HTA) y obesidad abdominal, en tratamiento con irbesartán-hidroclorotiazida 300/12,5 $\mathrm{mg} /$ día y atorvastatina $20 \mathrm{mg}$ al día.

En la exploración física destacaba una cianosis en tobillo y dedos del pie izquierdo, con lesiones puntiformes eritematovioláceas en primer dedo (figura 1). Los pulsos estaban conservados a todos los niveles. El resto de la exploración, incluyendo toma de constantes, fue anodina.

Como pruebas complementarias se solicitaron una analítica de sangre y orina, y un electrocardiograma (ECG). En la analítica, únicamente se observó un aumento de CLDL (148 mg/dl). El ECG no mostró alteraciones.

Ante la sospecha de alteración vascular con lesiones dérmicas características de ateroembolia en una paciente con múltiples FRCV, se derivó a consulta de Cirugía Vascular para valoración y estudio, quedando la paciente ingresada.
Durante su ingreso a cargo de dicho servicio, y con la valoración del servicio de Medicina Interna y Hematología, se solicitaron como pruebas complementarias una analítica con hemograma, bioquímica, PCR, coagulación, estudio de autoinmunidad y de trombofilia. Como parámetros patológicos se encontró una PCR elevada, un hipotiroidismo subclínico, eosinofilia y alteración genética (portadora heterocigoto del gen de la mutación G20210A) relacionada con el aumento del riesgo trombótico.

Para estudiar la posible afectación de placas de ateroma a otros niveles se realizó un ecodoppler de troncos supraórticos, ecocardiograma y angioTAC. Se encontraron placas de ateroma calcificadas en arteria ilíaca interna y femoral común izquierda, sin estenosis significativas.

Durante el ingreso hospitalario, la paciente recibió tratamiento con prostaglandina E1 (Alprostadil) con evolución clínica favorable e indicando al alta ácido acetilsalicílico $100 \mathrm{mg}$ al día y aumento de dosis de atorvastatina a $40 \mathrm{mg}$ al día, junto con el resto de su tratamiento habitual.

Transcurridos casi nueve meses, la paciente sigue revisiones en Cirugía Vascular y en nuestra consulta de Atención Primaria, refiriendo leve mejoría del dolor, pero persistiendo las lesiones dérmicas. Mantiene presión arterial y cLDL por debajo de objetivos.

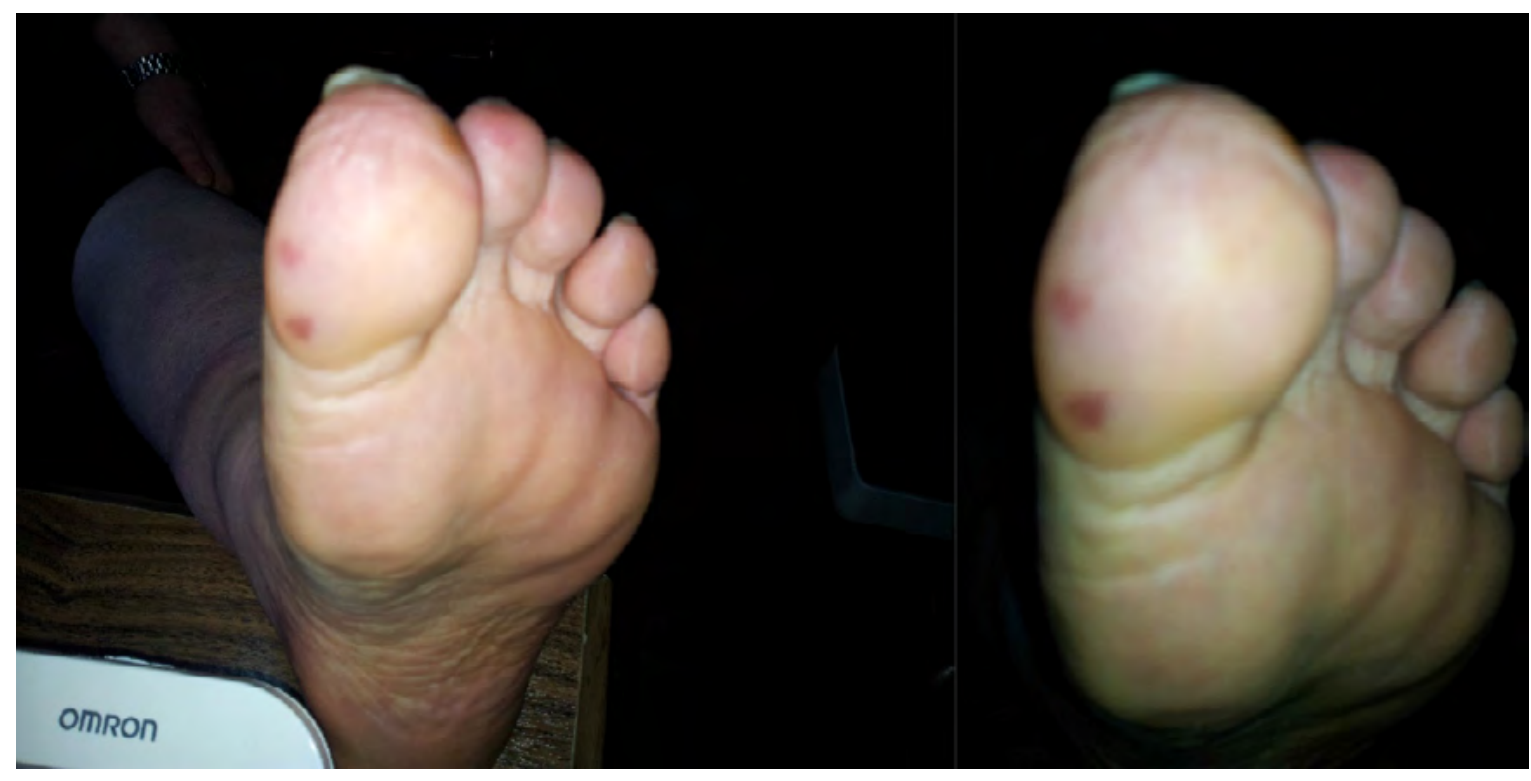

Figura 1. Lesiones puntiformes eritematovioláceas en primer dedo pie izquierdo. 


\section{COMENTARIOS}

La AEC es una entidad poco frecuente, cuya incidencia se ha incrementado en las últimas décadas y se ha estimado en 0,8 por 100.000 habitantes $^{6,7}$. Este aumento es consecuencia de una mayor población susceptible a la enfermedad (mayor longevidad, con aumento de factores de riesgo como diabetes, obesidad, hipertensión, tabaquismo y dislipidemia) que, a su vez, se expone a los factores que la desencadenan (cirugía cardiovascular, procedimientos endovasculares, tratamientos anticoagulantes y trombolisis) ${ }^{1-3}$.

Debido a la diversidad de la presentación clínica de esta enfermedad y a su escasa prevalencia, junto con el hecho de ser la biopsia el método de elección diagnóstico, suele estar infradiagnosticada?. Por ello, es muy importante la sospecha clínica para identificar correctamente la AEC.

Su patogenia se basa en la emisión de émbolos de colesterol provenientes de la ulceración de una placa ateroesclerótica. Estos émbolos son pequeños y generalmente numerosos, afectando a capilares, arteriolas y pequeñas arterias, produciendo isquemia y necrosis ${ }^{1-3}$. Cuando se compara el material embolizado con el área clínicamente afecta, la embolia resulta pequeña con respecto a los síntomas, debido a que se produce una respuesta inflamatoria que generaliza el problema ${ }^{8}$. Este cuadro es recurrente si no se trata la fuente de los mismos ${ }^{8}$. En un 30-80 \% de los pacientes afectos se evidencia una cirugía o angiografía en días previos a la embolia $^{5}$. Se ha estimado que el $1 \%$ de los cateterismos coronarios practicados puede producir fallo renal por $\mathrm{AEC}^{9}$. Pero también se ha observado un porcentaje elevado que aparece espontáneamente, sin factores desencadenantes ${ }^{8}$, como en el caso que hemos expuesto.

La presentación clínica depende de la cantidad, el tamaño, la composición y estabilidad del émbolo, y el órgano afecto $^{8}$. Las manifestaciones más comunes son las cutáneas, renales y digestivas ${ }^{1,2,7,10}$.

El $35 \%$ de los pacientes con AEC presenta manifestaciones cutáneas ${ }^{7}$, con livedo reticularis $\mathrm{y} / \mathrm{o}$ cianosis en unos o varios dedos (blue toe syndrom) sin anormalidades sensoriales ni de la temperatura y con pulsos distales palpables. La presencia de ambos es más específica de la AEC. Con menos frecuencia se puede encontrar una gangrena o ulceración distal, nódulos superficiales y profun$\operatorname{dos}^{1,2,7,9,10}$.
Se ha estimado que el riñón está implicado en un $75 \%$ de los pacientes ${ }^{7}$. La forma más común es el fallo renal agudo entre el tercer y octavo día de la manipulación intravascular, que se suele acompañar de HTA de inicio abrupto, y puede haber alteraciones en el sedimento urinario. También se han descrito casos de evolución subaguda (el deterioro se produce en semanas) o formas crónicas que son asintomáticas (meses o años) ${ }^{1,2,7}$. La recuperación renal tras este cuadro solo se da en un $25 \%$ de la población, necesitando diálisis en el $40 \%$ de los casos ${ }^{3}$.

Las manifestaciones en el tubo digestivo son frecuentes $(25-50 \%)^{7}$. El síntoma más común es el dolor abdominal por isquemia de asas o pancreatitis isquémica ${ }^{1,2,7}$. También puede haber diarrea o sangrado gastrointestinal ${ }^{10}$.

Las manifestaciones oculares o neurológicas son menos comunes ${ }^{7}$. Más raramente se han descrito alteraciones pulmonares y cardiológicas ${ }^{10}$. Otra forma de presentación es la forma diseminada con fallo multiorgánico, que no suele ocurrir espontáneamente ${ }^{8}$.

Los síntomas constitucionales como fiebre, anorexia, pérdida de peso, fatiga y mialgias son manifestaciones frecuentes consecuencia de la respuesta inflamatoria que se desencadena ${ }^{2}$.

Los exámenes de laboratorio pueden mostrar signos de inflamación: eosinofilia, hipocomplementemia, aumento de PCR y/o VSG. También se puede observar signos de fallo renal ${ }^{1,2,5,10}$. Es necesario descartar gammapatías monoclonales, enfermedades autoinmunes y vasculitis sistémicas ${ }^{9}$. En el caso clínico que se ha presentado, únicamente se objetivó un aumento de eosinófilos y de la PCR.

No existe tratamiento específico para la $A E C^{1,2,4,10}$. $\mathrm{Su}$ inicio debe ser lo más precoz posible, ya que su retraso hace que exista más daño y menos probable sea su recuperación ${ }^{3}$. Las medidas a tomar se dividen artificialmente en dos grupos: las encaminadas a evitar la reaparición de la EAC y las que intentan disminuir la isquemia de los órganos afectos $^{1-4,7}$.

Entre las primeras destacan el control estricto de los FRCV (HTA, diabetes, tabaco e hipercolesterolemia) y evitar la exposición del paciente a factores desencadenantes (anticoagulantes, trombolíticos e intervencionismo endovascular) ${ }^{1,2,7}$. El uso de antiagregantes plaquetarios parece razonable por 
su efecto favorable en otras manifestaciones de la aterosclerosis, sin embargo no hay evidencia directa para la prevención de la $A E C^{1,2}$.

Entre el segundo grupo de medidas, se encuentran los corticoides y los análogos de prostaglandinas. Los corticoides pretenden mejorar el componente inflamatorio ${ }^{3,5}$ y los análogos de prostaglandinas presentan una acción vasodilatadora y antiagregante $^{3}$. La terapia combinada no ha conseguido la recuperación de la función renal en todos los pacientes, pero sí los síntomas extrarrenales ${ }^{3}$.

Varios estudios han demostrado que las medidas preventivas disminuyen la mortalidad de los enfermos con AEC. Por el contrario, sigue siendo muy debatida la utilidad de las medidas específicas de esta enfermedad ${ }^{3}$.

Por lo tanto, se trata de una entidad poco común pero que debemos tener en cuenta, a pesar de la inespecificidad de sus manifestaciones clínicas, por su elevada morbimortalidad y la necesidad de instaurar un tratamiento temprano. El diagnóstico de sospecha se puede realizar ante un paciente con lesiones avanzadas de arterioesclerosis, con múltiples FRCV, que se suele exponer a factores predisponentes y que presenta manifestaciones cutáneas o renales de ateroembolia. Los datos de laboratorio pueden apoyar la sospecha diagnóstica.

Para finalizar, podemos afirmar que el médico de Atención Primaria juega un papel primordial en el diagnóstico de AEC, porque suele ser el primer profesional al que los pacientes consultan, genera una sospecha diagnóstica, gestiona un adecuado proceso asistencial para su estudio y tratamiento inmediato, y presenta mayor accesibilidad para el control de los FRCV para posteriormente evitar recurrencias.

\section{BIBLIOGRAFÍA}

1. Quinones A, Saric M. The cholesterol emboli syndrome in atherosclerosis. Curr Atheroscler Rep. 2013;15(4):315.

2. Kronzon I, Saric M. Cholesterol embolization syndrome. Circulation. 2010;122(6):631-41.

3. Sevillano-Prieto AM, Hernández E, Caro J, Molina M, Gutiérrez E, Morales E, et al. Ateroembolia de colesterol y tratamiento combinado con esteroides e iloprost. Nefrología. 2012;32(6):824-828.

4. Heras M, Salinas Moreno S, Fernández-Reyes M, Sánchez R. Muerte súbita en paciente con ateroembolismo de colesterol. Nefrología. 2009;29(3):275-6.

5. Lawson JM. Cholesterol crystal embolization: more common than we thought?. AJG. 2001;96(12):3230-2.

6. Moll Camps JJ, Castro Forns M, Peraire Navarro M, Martín Plata C. Revisión de la enfermedad por embolismo de cristales de colesterol. Rev Clin Esp. 2004;204(6):320-2.

7. Moya E, Arévalo J, Rodríguez-García JL, Gaudó J, Blancas R. Cianosis. En: Rodríguez García JL. Diagnóstico y tratamiento médico. Madrid: Marbán; 2009 p.7-13.

8. Bechara L. Nuevo enfoque para el tratamiento de las causas de ateroembolia. RACCV. 2011;9(3):175-82.

9. Biesenbach P, Gremmel T, Hörl W, Kain R, Säemann MD. Gross proteinuria and subacute renal failure after coronary angiographay- a case report of cholesterol cristal embolization. WKW. 2010;122:251-4.

10. Germain P, Dumoulin C, Rakatonovao H, Etienne G, Malterre L, Bouillot S, et al. Cholesterol crystal embolization simulating focal myositis. Joint Bone Spine. 2001;68:267-9. 